\title{
Gender differences in variables associated with sleep quality in chronic tension type headache
}

\author{
Margarita Cigarán-Méndez, Juan J. Fernández-Muñoz, Esperanza Navarro- \\ Pardo, Carmen Jiménez-Antona, Paula Parás-Bravo, Francisco Alburquerque- \\ Sendín \& César Fernández-De-Las-Peñas
}

To cite this article: Margarita Cigarán-Méndez, Juan J. Fernández-Muñoz, Esperanza NavarroPardo, Carmen Jiménez-Antona, Paula Parás-Bravo, Francisco Alburquerque-Sendín \& César Fernández-De-Las-Peñas (2017): Gender differences in variables associated with sleep quality in chronic tension type headache, Women \& Health, DOI: 10.1080/03630242.2017.1372845

To link to this article: http://dx.doi.org/10.1080/03630242.2017.1372845

Accepted author version posted online: 18 Sep 2017.

\section{Submit your article to this journal $\sqsubset$}

View related articles $־$

View Crossmark data 


\section{Gender Differences in Variables Associated with Sleep Quality in Chronic Tension Type Headache}

Margarita Cigarán-Méndez ${ }^{1} \mathrm{PhD}$; Juan J. Fernández-Muñoz ${ }^{1} \mathrm{PhD}$; Esperanza NavarroPardo $^{2} \mathrm{PhD}$; Carmen Jiménez-Antona ${ }^{3} \mathrm{PT}, \mathrm{PhD}$; Paula Parás-Bravo ${ }^{4} \mathrm{PT}, \mathrm{PhD}$; Francisco Alburquerque-Sendín ${ }^{\mathbf{5}}$ PT, PhD; César Fernández-de-las-Peñas ${ }^{\mathbf{3}}$ PT, PhD, DMSc

(1) Department of Psychology, Universidad Rey Juan Carlos, Alcorcón, Spain

(2) Department of Developmental and Educational Psychology, Universitat de Valencia, Spain

(3) Department of Physical Therapy, Occupational Therapy, Rehabilitation and Physical Medicine, Universidad Rey Juan Carlos, Alcorcón, Spain

(4) Department of Nursing, Universidad de Cantabria, Spain

(5) Department of Physical Therapy, Universidad de Córdoba, Córdoba, Spain

Address for reprint requests / corresponding author.

César Fernández de las Peñas, Telephone number: + 34914888884

Facultad de Ciencias de la Salud, Universidad Rey Juan Carlos, Fax number: + 3491 48889 57, Avenida de Atenas s/n, 28922 Alcorcón, Madrid, SPAIN

E-mail address: cesar.fernandez@urjc.es

The study protocol was approved by the ethics board of the Universidad Rey Juan Carlos.

The authors declare no conflicts of interest with the content of this article.

Short title: Gender differences in tension type headache

\section{Abstract}

We aimed to evaluate gender differences in the relationships between headache features, sleep quality, anxiety, depressive symptoms and burden of headache in 193 
patients (73\% women) with chronic tension type headache (CTTH). Sleep quality was assessed with the Pittsburgh Sleep Quality Index. Headache features were collected with a four-week diary. The Hospital Anxiety and Depression Scale was used to assess anxiety/depressive symptoms. Headache Disability Inventory was used to evaluate the burden of headache. In men with CTTH, sleep quality was positive correlated with headache frequency $(\mathrm{r}=0.310 ; \mathrm{P}=0.018)$, emotional $(\mathrm{r}=0.518 ; \mathrm{P}<0.001)$ and physical $(\mathrm{r}=0.468 ; \mathrm{P}<0.001)$ burden of headache, and depressive symptoms $(\mathrm{r}=0.564 ; \mathrm{P}<0.001)$. In women, positive correlations were observed between sleep quality and headache intensity $(\mathrm{r}=0.282 ; \mathrm{P}<0.001)$, headache frequency $(\mathrm{r}=0.195 ; \mathrm{P}=0.021)$, emotional burden $(\mathrm{r}=0.249 ; \mathrm{P}=0.004)$ and depressive symptoms $(\mathrm{r}=0.382 ; \mathrm{P}<0.001)$. The results of stepwise regression analyses revealed that depressive symptoms and emotional burden of headache explained $37.2 \%$ of the variance in sleep quality in men $(\mathrm{P}<0.001)$, whereas depressive symptoms and headache intensity explained $17.4 \%$ of the variance in sleep quality in women $(\mathrm{P}<0.001)$ with CTTH. Gender differences associated with poor sleep should be considered for proper management of individuals with CTTH.

Keywords: Gender, tension type headache, sleep quality, pain, depressive symptoms.

\section{Introduction}

Tension type headache (TTH) is a frequently occurring headache disorder, showing a global prevalence of $42 \%$ (Ferrante et al. 2013), and has important socioeconomic impact (Dowson 2015). In the Global Burden of Disease Study 2010, TTH was the second most prevalent disorder in the world (Vos et al. 2012). Primary headache disorders, including TTH, have notable gender differences in their prevalence 
(Jarsen, and Stovner 2008). In fact, TTH has a female: male prevalence ratio about 3:1 (Manzoni and Stovner 2010).

Emotional stress and sleep disturbances are the most frequent trigger factors for headache attacks in patients with TTH (Wang et al 2013). Gender differences are related to these triggers because women are 1.3 to 2.0 times as likely to have poor sleep than men (Reyner, Horne and Reyner. 1995), and the female: male ratios for depressive and anxiety symptoms are 1.2:1 and 1.8:1, respectively (Lampl 2016). Further, headache diagnoses (migraine and TTH) and female gender have been significantly associated with depression in $74.7 \%$ of cases (McMurtrayet al. 2013). In fact, gender differences have been observed in pain perception (Maureret al. 2016), brain structure development and function (Ingalhalikar et al. 2014), life experiences and cultural expectations (Springer, Stellman and Jordan-Young 2014), and biopsychosocial factors associated with the pain experience (Racine et al. 2012a).

It has been previously suggested that headache relationships differ according to gender because the gender influence on primary headache phenotype is a complex process and needs examination in further studies (Fumal and Schoenen 2008). A better understanding of gender differences in the relationships between headache clinical features, sleep quality, mood disorders (i.e., anxiety and depressive symptoms) and headache burden in individuals with TTH can assist clinicians in determining better therapeutic programs adapted to gender. However, no study of which we are aware has previously investigated this topic. Therefore, the purpose of the current study was to evaluate gender differences in the relationship between headache clinical features, sleep quality, anxiety, depressive symptoms and burden of headache in men and women with TTH. Because mood disorders and sleep disturbances are generally more associated 
with headache frequency, we included individuals with chronic tension type headache (CTTH).

\section{Methods}

\section{Participants}

Patients with a diagnosis of CTTH were recruited from different university-based hospitals between September 2014 and June 2016. Diagnosis was conducted according to the International Classification of Headache Disorders criteria, third edition (ICHDIII 2013), codes 2.2, 2.3, by two neurologist experts in headache (ICHD-III 2013). To be included, participants had to describe all the pain features typical of TTH: bilateral location, pressing and tightening pain, moderate intensity ( $\leq 7$ on a 10-points numerical pain rate scale, NPRS) and no aggravation of headache during physical activity. Patients also should not report more than one photophobia or phonophobia and neither moderate nor severe nausea nor vomiting as indicated by the ICHD-III (2013).

Participants were excluded if they presented with: 1) episodic headaches; 2) other primary/secondary headache, including medication overuse headache as defined by the ICHD-III; 3) history of cervical or head trauma (i.e., whiplash); 4) history of cervical herniated disk or cervical osteoarthritis on medical record; 5) any systemic degenerative disease, e.g., rheumatoid arthritis, or lupus erythematous; 6) diagnosis of fibromyalgia syndrome; 7) receiving anesthetic block or physical therapy in the previous 6 months; 8) abuse of stimulating substances; or, 9, pregnancy. All participants read and signed an informed consent form prior to their participation. The local Ethics Committee approved the study design (HUFA 14/104, HRJ 07/14). 


\section{Sleep Quality}

The Pittsburgh Sleep Quality Index (PSQI) was used to assess sleep quality (Cole, Dubois and Kosinski 2007). This questionnaire assesses sleep quality over a onemonth period through a standardized questionnaire consisting of 19 self-rated questions and five questions answered by bed- or room- mates. The items use varying response categories recording usual bed time, usual wake time, number of actual hours slept, and number of minutes to fall asleep. All questions are answered on a Likert-type scale (03). The sum of all answers gives a global score (total possible range $0-21$ ) where higher score indicates worse sleep quality (Buysse 1989). The PSQI has shown good internal consistency $(\alpha: 0.83)$ and test-retest reliability (r: 0.85). A total score $>8.0$ is indicative of poor sleep quality (Carpenter and Andrykowski 1998).

\section{Clinical Outcomes - Headache Diary}

A headache diary kept for four weeks was used to substantiate the diagnosis and to record the headache clinical pain features (Phillip, Lyngberg and Jensen 2007). On this diary, patients registered the number of days with headache (days/week), the headache intensity on an 11-point numerical pain rating scale (Jensen et al. 1999) (NPRS; 0: no pain, 10: the maximum pain), and the duration of each headache attack (hours/day).

\section{Hospital Anxiety and Depression Scale (HADS)}

The HADS is a 14 items self-report screening scale, seven items for anxiety (HADS-A) and seven for depressive symptoms (HADS-D), developed to indicate the presence of anxiety and depressive symptoms (Zigmond and Snaith 1983). Each item is scored on a Likert scale (0-3) giving a maximum subscale score of 21 points for each subscale (Herrmann-Lingen, Buss and Snaith 2011). The HADS has shown good 
validity and internal consistency (Cronbach's $\alpha$ : 0.84) for being used in individuals with headache (Juang et al. 1999).

\section{Headache Disability Inventory (HDI)}

The HDI assesses the burden of headache using 25 items that inquire about the perceived impact of headache on emotional functioning and daily activities (Jacobson et al. 1994). Possible answers for each item are YES (4 points), SOMETIMES (2 point) and NO (0 points). Thirteen items assess the emotional burden of headache (HDI-E, maximum score: 52) and the remaining 12 items assess the physical burden (HDI-P,

maximum score: 48). A greater score suggests a greater burden of headache. The HDI exhibited good stability at short $(r=0.93-0.95)$ and long-term $(r=0.76-0.83)$ (Jacobson et al. 1995).

\section{Statistical analysis}

Means and confidence intervals were calculated for all outcomes by gender. The Kolmogorov-Smirnov test showed that all data exhibited a normal distribution $(\mathrm{P}>0.05)$. To determine the relationship between the dependent measure (sleep quality- Pittsburgh Sleep Quality Index) and the independent variables, several Pearson product-moment correlation coefficients were calculated. The independent variables included in the main analysis were: age, years with pain, headache intensity, headache frequency, headache duration, depressive symptoms (HADS-D), anxiety (HADS-A), emotional burden of the headache (HDI-E) or physical burden of the headache (HDI-P). Statistical analyses were also used to check for multicollinearity and shared variance between the outcomes. All correlation analyses were conducted in men and women, separately.

A regression model was used to assess the independent variables that contributed significantly to the variance in sleep quality. To examine the proportions of explained variance of sleep quality, a hierarchical regression analysis was conducted by gender. 
The significance criterion of the critical $\mathrm{F}$ value for entry into the regression equation was set at $\mathrm{P}<0.05$. To analyze the contribution of depressive symptoms (HADS-D) and the emotional burden of the headache (HDI-E) to sleep quality in males, and the contribution of depressive symptoms (HADS-D) and the intensity of headaches to sleep quality in females, these independent variables were entered into a regression model in two steps. Depressive symptomatology was entered into the model at the first step, followed by emotional burden, in males, or headache intensity, in females at the second step. Changes in $R^{2}$ were reported after each step of the regression model to determine the association of the additional variables. Last, variables that significantly contributed to the score on the PSQI (sleep quality) were selected for inclusion into parsimonious final regression model.

\section{Results}

Two hundred and fifty ( $\mathrm{n}=235$ ) individuals with headache were screened for possible eligibility criteria. Of these, 52 men and 141 women satisfied all the criteria, agreed to participate and signed the informed consent. The remaining 42 were excluded for the following reasons: co-morbid migraine $(n=30)$, previous neck trauma $(n=4)$, medication overuse headache $(n=4)$, or fibromyalgia syndrome diagnosis $(n=4)$. No significant differences were observed between men and women with CTTH for any outcome (all, $\mathrm{P}>0.166)$ except for depressive symptoms $(\mathrm{F}=1.720 ; \mathrm{P}=0.014)$ : women had higher levels of depressive symptoms than men (Table 1). 


\section{Correlation Analysis}

Within men with CTTH, significant positive correlations were observed between the Pittsburgh Sleep Quality Index and headache frequency ( $\mathrm{r}=0.310 ; \mathrm{P}=0.018)$, HDI-E $(\mathrm{r}=0.518 ; \mathrm{P}<0.001)$, HDI-P $(\mathrm{r}=0.468 ; \mathrm{P}<0.001)$ and HADS-D $(\mathrm{r}=0.564 ; \mathrm{P}<0.001)$ : the higher the frequency of headache attacks, the higher emotional and physical burden of headache and the higher the depressive symptoms, the worse the sleep quality in men with CTTH.

Within women with CTTH, significant positive correlations were found between the Pittsburgh Sleep Quality Index and headache intensity $(r=0.282 ; \mathrm{P}<0.001)$, headache frequency $(\mathrm{r}=0.195 ; \mathrm{P}=0.021)$, HDI-E $(\mathrm{r}=0.249 ; \mathrm{P}=0.004)$, and HADS-D $(\mathrm{r}=0.382$; $\mathrm{P}<0.001)$ : the higher the intensity and frequency of headaches, the higher emotional burden of headache and the higher the depressive symptoms, the worse the sleep quality in women with CTTH (Table 2).

Significant correlations also existed among the independent variables $(0.168<\mathrm{r}<$ 0.729; Table 2), with no multicollinearity (defined as $r>0.80$ ); therefore, each variable was included into regression analyses.

\section{Regression Analyses}

Within men with CTTH, depressive symptoms approximately contributed $32 \%$ $(\mathrm{P}<0.001)$, and emotional burden of the headache (HDI-E) contributed an additional 5\% $(\mathrm{P}<0.001)$ of the variance of the Pittsburgh Sleep Quality Index (Table 3). When combined, these two factors explained $37.2 \%$ of the variance in sleep quality $\left(\mathrm{r}^{2}\right.$ adjusted: $0.372, \mathrm{~F}=14.500, \mathrm{P}<0.001)$. Within women with $\mathrm{CTTH}$, depressive symptoms contributed $15 \%(\mathrm{P}<0.001)$, and headache pain intensity contributed an additional $2 \%$ $(\mathrm{P}<0.001)$ of the variance of the Pittsburgh Sleep Quality Index. When combined, both 
factors explained $17.4 \%$ of the variance of sleep quality ( $\mathrm{r}^{2}$ adjusted: $0.174, \mathrm{~F}=14.510$, $\mathrm{P}<0.001)$

\section{Discussion}

The current study found that depressive symptoms and emotional burden of headache in men and depressive symptoms and the intensity of headache in women were significantly associated with sleep quality in individuals with CTTH. Current findings would suggest that depressive symptoms are a frequent factor associated with poor sleep quality in both men and women with $\mathrm{CTTH}$, but some gender differences were observed for other associated factors.

Individuals with TTH exhibit co-morbid depressive symptoms (Beghi et al. 2010) and sleep disturbances (Uhlig et al. 2014); however, no previous studies of which we are aware have investigated the associations of these factors stratified by gender. Our study identified that depressive symptoms contributed to $32 \%$ of the variance of sleep quality in men but only contributed to $15 \%$ of the variance in women with CTTH. Although depression is a factor clearly associated with sleep disturbances, and the prevalence of depressive symptoms is similar in men and women with chronic headache (Lampl et al. 2016; Spiegelhalder et al. 2013), the interesting finding of the current study was that this association was almost double in men than in women. It seems that biological, cultural, and experiential factors may underlie gender differences in the phenomenology of mood disorders (Altemus et al. 2014). For instance, women are more likely to describe a feeling of "shortness of breath", "faintness", and "feeling smothered"' and tend to fear the physical symptoms of panic, whereas men more often fear the social consequences of depressive symptoms. A possible explanation for this finding is that women are more likely to receive positive reinforcement when expressing 
concerns about their symptoms that could encourages self-focused attention and more perceived physical discomfort. In fact, under conditions of perceived threat, men are more likely to escape or cope by taking action and women are more likely to express social behavior and seek support from others (Taylor et al. 2000). Therefore, proper management of depressive symptoms by improving copying and cognitive strategies should consider differences between men and women with CTTH. This hypothesis is supported by a study suggesting that women tend to cope better with pain when employing pain attention focus or reinterpreting pain sensation strategies, whereas distraction may be more efficient in men (Keogh and Herdenfeldt 2002).

The results of the multiple regression analysis revealed that the emotional burden of the headache also contributed an additional 5\% to sleep quality in men, but not in women, with CTTH. This finding maybe related to the fact that emotional factors, particularly anxiety, seem to be more strongly related to pain perception in males (Jones et al. 2002; Jones, Zachariae and Arendt-Nielsen 2003). In fact, Thorn et al (2004) determined that gender differences in response to pain stimulus may be partially attributed to their disparities in personality traits, i.e., emotional vulnerability, between men and women. It is therefore possible that personality or emotional vulnerability has a more direct role in men than in women with chronic headache.

Finally, the results of the stepwise regression analysis showed that the intensity of headache pain explained a small proportion of the variance $(2 \%)$ of sleep quality in women, but not men, with CTTH. Previous reviews concluded that women exhibit significantly greater pain sensitivity than men for all painful modalities (Fillingim et al. 2009); however, a more recent systematic review found strong scientific evidence that females have greater sensitivity to pressure and thermal stimuli, but not the remaining stimuli, than males (Racine et al. 2012b). Additionally, activation of conditioned pain 
modulation analgesia is greater in men than in female (Arendt-Nielsen, Sluka and Nie 2008). Therefore, gender differences in nociceptive pain processing would explain our results.

Uncertainty over biological mechanisms withstanding in gender differences, our results have potential clinical implications since emotional stress, depressive symptoms, and sleep represent modifiable risk factors implicated in the progression of episodic to chronic headaches (Rains 2008). Our results suggested that depressive symptomatology was the most influential factor related to sleep quality in women men and women with CTTH, supporting that a psychological approach should be effective for the management of this headache condition (Verhagen et al. 2009). Nevertheless, the emotional burden of headache and the intensity of headache were differently associated with sleep quality in men and women with CTTH. Therefore, current findings would suggest that management of men with $\mathrm{CTTH}$ should focus also include interventions targeted to decrease the emotional burden of headache (copying strategies or cognitive behavioral techniques), whereas management of women with CTTH should focus on intervention targeting nociceptive pain mechanisms related to headache intensity.

Although strengths of this study included a large sample size and the inclusion of CTTH patients meeting the most updated diagnostic criteria, the use of daily diaries and the use of standardized instruments, our study had its limitations. First, we included a sample consisted mainly of CTTH patients referred to a tertiary headache center and thus not representative of the general population. In fact, we only included patients with CTTH, so our results should not be extrapolated to patients with frequent episodic TTH or other primary headaches such as migraine. Second, the study was cross-sectional, and thus causal relations are thus impossible to ascertain. Third, the HADS is a screening rather than diagnostic instrument for depressive and anxiety symptoms, with a tendency 
to underestimate prevalence of both disorders (Steel et al. 2014). It was surprising that the prevalence of anxiety and depressive symptoms observed in our sample of CTTH were low because the high female-to-male ratio, the chronic nature of the headache, and the population being drawn from a general neurology clinic, rather than a population sample or primary care clinic, may have increased the frequency of co-morbid depressive symptoms in our sample. It is hence possible that the inclusion of people with higher levels of depressive symptoms or anxiety could yield different results; although this is unlikely. Fourth, we did not evaluate the influence of socioeconomic status, which is a factor associated with TTH and sleep quality in women because women are more susceptible to socioeconomic influence (Chu et al. 2013).

\section{Conclusions}

In this study, depressive symptoms and emotional burden of headache explained $37.2 \%$ of the variability in sleep quality in men with $\mathrm{CTTH}$, whereas depressive symptoms and headache intensity explained $17.4 \%$ of the variability in sleep quality in women with CTTH. Our findings would suggest that depressive symptomatology is a frequent factor associated with poor sleep quality in both individuals with $\mathrm{CTTH}$, but some gender differences were observed in other associated factors. Future longitudinal studies will help to determine further the clinical implications of these findings.

\section{References}

Altemus, M., Sarvaiya, N., Neill., and C. Epperson. 2014. Sex differences in anxiety and depression clinical perspectives. Frontiers in neuroendocrinology 35: 32030.

Arendt-Nielsen, L., Sluka, K.A., and H.L. Nie. 2008. Experimental muscle pain impairs descending inhibition. Pain 140: 465-71. 
Beghi, E., Bussone, G., D'Amico, D., Cortelli, P., Cevoli, S., Manzoni, G.C., Torelli, P., Tonini, M.C., Allais, G., De Simone, R., D'Onofrio, F., Genco, S., Moschiano, F., Beghi, M., and S. Salvi. 2010. Headache, anxiety and depressive disorders: the HADAS study. The journal of headache and pain 11: 141-50.

Buysse, D.J., Reynolds, C.F., Monk, T.H., Berman, S.R., and D.J. Kupfer. 1989.The Pittsburgh Sleep Quality Index: a new instrument for psychiatric practice and research. Psychiatry research 28: 193-213.

Carpenter, J.S., and M.A. Andrykowski. 1998. Psychometric evaluation of the Pittsburgh Sleep Quality Index. Journal of psychosomatic research 45: 5-13.

Chu, M.K., Kim, D.W., Kim, B.K., Kim, J.M., Jang, T.W., Park, J.W., Lee, K.S., and S.J. Cho. 2013. Gender-specific influence of socioeconomic status on the prevalence of migraine and tension-type headache: the results from the Korean Headache Survey. The journal of headache and pain 14: 82.

Cole, J.C., Dubois, D., and Kosinski, M. 2007. Use of patient-reported sleep measures in clinical trials of pain treatment: a literature review and synthesis of current sleep measures and a conceptual model of sleep disturbance in pain. Clinical therapeutics 29: 2580-2588.

Dowson, A. 2015. The burden of headache: global and regional prevalence of headache and its impact. International journal of clinical practice. Supplement 182: 3-7.

Ferrante, T., Manzoni, G.C., Russo, M., Camarda. C., Taga, A., Veronesi, L., Pasquarella, C., Sansebastiano, G., and P. Torelli. 2013. Prevalence of tension-type headache in adult general population: the PACE study and review of the literature. Neurological sciences: official journal of the Italian Neurological Society and of the Italian Society of Clinical Neurophysiology 34: S137-8. 
Fillingim, R.B., King, C.D., Ribeiro-Dasilva, M.C., Rahim-Williams, B., and III J.L.Riley. 2009. Sex, gender, and pain: a review of recent clinical and experimental findings. The journal of pain : official journal of the American Pain Society 10: 447-85.

Fumal, A., and J. Schoenen. 2008. Tension-type headache: Current research and clinical management. The Lancet Neurology 7: 70-83.

Herrmann-Lingen, C., Buss, U., and R.P. Snaith. 2011. Hospital Anxiety and Depression Scale - Deutsche Version (HADS-D). Berna, Suiza: Verlag Hans Huber.

ICHD-III International Classification of Headache Disorder. 2013. Headache Classification Subcommittee of the International Headache Society, 3nd edition. Cephalalgia 33: 629-808.

Ingalhalikar, M., Smith, A., Parker, D., Satterthwaite, T., Elliot, M., Ruparel, K., Hakonarson, H., Gur, R.C., Gur, R.E., and R. Verma. 2014. Sex differences in the structural connectome of the human brain. Proceedings of the National Academy of Sciences of the United States of America 111:823-828.

Jacobson, G.P., Ramadan, N.M., Norris, L., and C.W. Newman. 1994.The Henry Ford Hospital Headache Disability Inventory. Neurology 44; 837-42.

Jacobson, G.P., Ramadan, N.M., Norris, L., and C.W. Newman. 1995. Headache disability inventory (HDI): short-term test-retest reliability and spouse perceptions. Headache 35: 534-9.

Jarsen, R., and L.J. Stovner. 2008. Epidemiology and comorbidity of headache. The Lancet Neurology 7:354-361.

Jensen, M.P., Turner, J.A., Romano, J.M., and L. Fisher. 1999. Comparative reliability and validity of chronic pain intensity measures. Pain 83: 157-162. 
Jones, A., Spindler, H., Jorgensen, M.M., and R. Zachariae. 2002. The effect of situation evoked anxiety and gender on pain report using the cold pressor test. Scandinavian journal of psychology 43: 307-13.

Jones, A., Zachariae, R., and L. Arendt-Nielsen. 2003. Dispositional anxiety and the experience of pain: gender-specific effects. European journal of pain 7: 387-95.

Juang, K.D., Wang, S.J., Lin, C.H., and J.L Fuh. 1999. Use of the Hospital Anxiety and Depression Scale as a screening tool for patients with headache. Zhonghua yi хие za zhi (Taipei) 62: 749-55.

Keogh, E., and M. Herdenfeldt. 2002. Gender, coping and the perception of pain. Pain 97: 195-201.

Lampl, C., Thomas, H., Tassorelli, C., Katsarava, Z., Laínez, J.L., LantériMinet, M., Rastenyte, D., Ruiz de la Torre, E., Stovner, L.J., Andrée, C., and T.J Steiner. 2016a. Headache, depression and anxiety: associations in the Eurolight project. The journal of headache and pain 17: 59.

Manzoni, G.C., and L.J. Stovner. 2010. Epidemiology of headache. Handbook of clinical neurology 97: 3-22.

Maurer, A.J., Lissounov, A., Knezevic, I., Candido, K.D., and N.N. Knezevic.2016. Pain and sex hormones: a review of current understanding. Pain management 6: 285-96.

McMurtray, A.M., Saito, E.K., Diaz, N., Mehta, B., and B. Nakamoto. 2013. Greater frequency of depression associated with chronic primary headaches than chronic post-traumatic headaches. International journal of psychiatry in medicine 45: 227-36. 
Phillip, D., Lyngberg, A.C., and R. Jensen. 2007. Assessment of headache diagnosis: A comparative population study of a clinical interview with a diagnostic headache diary. Cephalalgia 27: 1-8.

Racine, M., Tousignant-Laflamme, Y., Kloda, L.A., Dion, D., Dupuis, G., and M. Choinière. 2012a. A systematic literature review of 10 years of research on sex/gender and experimental pain perception-Part 1: Are there really differences between women and men?. Pain 153: 602-618.

Racine, M., Tousignant-Laflamme, Y., Kloda, L.A., Dion, D., Dupuis, G., and M. Choinière. 2012b. A systematic literature review of 10 years of research on sex/gender and pain perception-Part 2: Do biopsychosocial factors alter pain sensitivity differently in women and men?. Pain 153: 619-635.

Rains JC. 2008. Chronic headache and potentially modifiable risk factors: screening and behavioral management of sleep disorders. Headache 48: 32-39.

Reyner, L., Horne, J., and A. Reyner. 1995. Gender- and age-related differences in sleep determined by home-recorded sleep logs and actimetry from 400 adults. Sleep 18: $127-134$.

Spiegelhalder, K., Regen, W., Nanovska, S., Baglioni, C., and D. Riemann. 2013. Comorbid sleep disorders in neuropsychiatric disorders across the life cycle. Current psychiatry reports 15: 364.

Springer, K., Stellman, J., and R. Jordan-Young. 2014. Beyond a catalogue of differences: a theoretical frame and good practice guidelines for researching sex/gender in human health. Social science \& medicine 74: 1817-1824.

Steel, Z., Marnane, C., Iranpour, C., Chey, T., Jackson, J.W., Patel, V., and D. Silove. 2014. The global prevalence of common mental disorders: a systematic review and meta-analysis 1980-2013. International journal of epidemiology 43: 476-493. 
Taylor, S., Klein, L., Lewis, B., Gruenewald, T., Gurung, R., and J. Updegraff. 2000. Biochemical responses to stress in females: tend-and-befriend, not fight-or fight. Psychological review 107: 411-429.

Thorn, B.E., Clements, K.L., Ward, L.C., Dixon, K.E., Kersh, B.C., Boothby, J.L., and W.F. Chaplin. 2004. Personality factors in the explanation of sex differences in pain catastrophizing and response to experimental pain. The Clinical journal of pain 20: $275-82$.

Uhlig, B.L., Engstrøm, M., Ødegård, S.S., Hagen, K.K., and T. Sand. 2014. Headache and insomnia in population-based epidemiological studies. Cephalalgia $34: 745-51$

Verhagen, A.P., Damen, L., Berger, M.Y., Passchier, J., and B.W. Koes. 2009. Behavioral treatments of chronic tension-type headache in adults: are they beneficial?. CNS neuroscience \& therapeutics 15: 183-205.

Vos, T., Flaxman, A.D., Naghavi, M., Lozano, R., Michaud, C., Ezzati, M., Shibuya, K., Salomon, J.A., Abdalla, S., Aboyans, V., et al. 2012.Years lived with disability (YLDs) for 1160 sequelae of 289 diseases and injuries 1990-2010: asystematic analysis for the Global Burden of Disease Study 2010. Lancet 380: 21632196.

Wang, J., Huang, Q., Li, N., Tan, G., Chen, L., and J. Zhou. 2013. Triggers of migraine and tension-type headache in China: a clinic-based survey. European journal of neurology 20: 689-96.

Zigmond, A.S., and R.P. Snaith. 1983. The hospital anxiety and depression scale. Acta psychiatrica Scandinavica 67: 361-70. 
Table 1: Clinical data of the sample by gender*

\begin{tabular}{|c|c|c|}
\hline Sex of participants & Factor & $\begin{array}{c}\text { Mean (95\% confidence } \\
\text { interval) }\end{array}$ \\
\hline \multirow{10}{*}{ Men $(n=52)$} & Age (year) & $45(42-48)$ \\
\hline & Years with pain & $11.1(7.3-14.9)$ \\
\hline & Headache intensity (NPRS, 0-10) & $6.6(6.1-7.1)$ \\
\hline & Headache duration (hours/attack) & $7.7(6.5-8.9)$ \\
\hline & Headache frequency (days/month) & $18.1(15.4-20.8)$ \\
\hline & Sleep quality (Pittsburg, 0-21) & $7.6(6.4-8.8)$ \\
\hline & HDI-E (0-52) & $(14.4-21.3)$ \\
\hline & HDI-P (0-48) & $22.0(19.1-25.0)$ \\
\hline & HADS-D $(0-2)$ & $6.9(5.9-7.7)$ \\
\hline & HADS-A $(0-21)$ & $10.1(8.6-11.6)$ \\
\hline \multirow{10}{*}{ Women } & Age (year) & $45(43-48)$ \\
\hline & Years with pain & $10.9(8.6-13.2)$ \\
\hline & Headache intensity (NPRS, 0-10) & $6.2(5.9-6.5)$ \\
\hline & Headache duration (hours/attack) & $7.5(6.8-8.2)$ \\
\hline & Headache frequency (days/month) & $16.7(15.2-18.2)$ \\
\hline & Sleep quality (Pittsburg, 0-21) & $8.3(7.6-9.0)$ \\
\hline & HDI-E (0-52) & $19.0(17.0-21.0)$ \\
\hline & HDI-P (0-48) & $22.7(20.8-24.6)$ \\
\hline & HADS-D (0-21)\# & $8.5(7.8-9.2)$ \\
\hline & HADS-A (0-21) & $9.9(9.0-10.8)$ \\
\hline
\end{tabular}

\# Significant differences between men and women $(\mathrm{P}<0.05)$

HDI: Headache Disability Inventory (E: Emotional; P: Physical); HADS:

Hospital Anxiety and Depression Scale (D: Depression; A: Anxiety) 
Table 2: Pearson-Product Moment Correlation Matrix

\begin{tabular}{|c|c|c|c|c|c|c|c|c|c|c|}
\hline & & 1 & 2 & 3 & 4 & 5 & 6 & 7 & 8 & 9 \\
\hline \multirow{10}{*}{$\begin{array}{c}\text { Men } \\
(\mathrm{n}=52)\end{array}$} & $\begin{array}{c}\text { 1. Pittsburg } \\
\text { questionnair } \\
\mathrm{e}\end{array}$ & & & & & & & & & \\
\hline & 2. Age & n.s. & & & & & & & & \\
\hline & $\begin{array}{l}\text { 3. Years } \\
\text { with pain }\end{array}$ & n.s. & n.s. & & & & & & & \\
\hline & $\begin{array}{l}\text { 4. Headache } \\
\text { Intensity }\end{array}$ & n.s. & n.s. & $0.298^{*}$ & & & & & & \\
\hline & $\begin{array}{l}\text { 5. Headache } \\
\text { Duration }\end{array}$ & n.s. & n.s. & n.s. & n.s. & & & & & \\
\hline & $\begin{array}{l}\text { 6. Headache } \\
\text { frequency }\end{array}$ & $0.310^{*}$ & n.s. & $\mathrm{n}_{\mathrm{s}}$ & & & & & & \\
\hline & 7. HDI-E & $\begin{array}{c}0.518^{*} \\
*\end{array}$ & & & & n.s. & $0.450^{* *}$ & & & \\
\hline & 8. HDI-P & $0.468^{*}$ & & n.s. & n.s. & n.s. & $0.312^{*}$ & $\begin{array}{c}0.727^{*} \\
*\end{array}$ & & \\
\hline & 9. HADS-D & $564 *$ & n.s. & n.s. & n.s. & n.s. & $0.477^{* *}$ & $\begin{array}{c}0.583^{*} \\
*\end{array}$ & $\begin{array}{c}0.484^{*} \\
*\end{array}$ & \\
\hline & $\begin{array}{l}\text { 10. HADS- } \\
\text { A }\end{array}$ & n.s. & n.s. & n.s. & n.s. & n.s. & $0.528^{*}$ & n.s. & n.s. & $\begin{array}{c}0.350 \\
*\end{array}$ \\
\hline \multirow{3}{*}{$(n=141$} & $\begin{array}{l}\text { 1. Pittsburg } \\
\text { questionnair } \\
\mathrm{e}\end{array}$ & & & & & & & & & \\
\hline & 2. Age & $0.225^{*}$ & & & & & & & & \\
\hline & $\begin{array}{l}\text { 3. Years } \\
\text { with pain }\end{array}$ & n.s. & $\begin{array}{c}0.196 \\
*\end{array}$ & & & & & & & \\
\hline
\end{tabular}




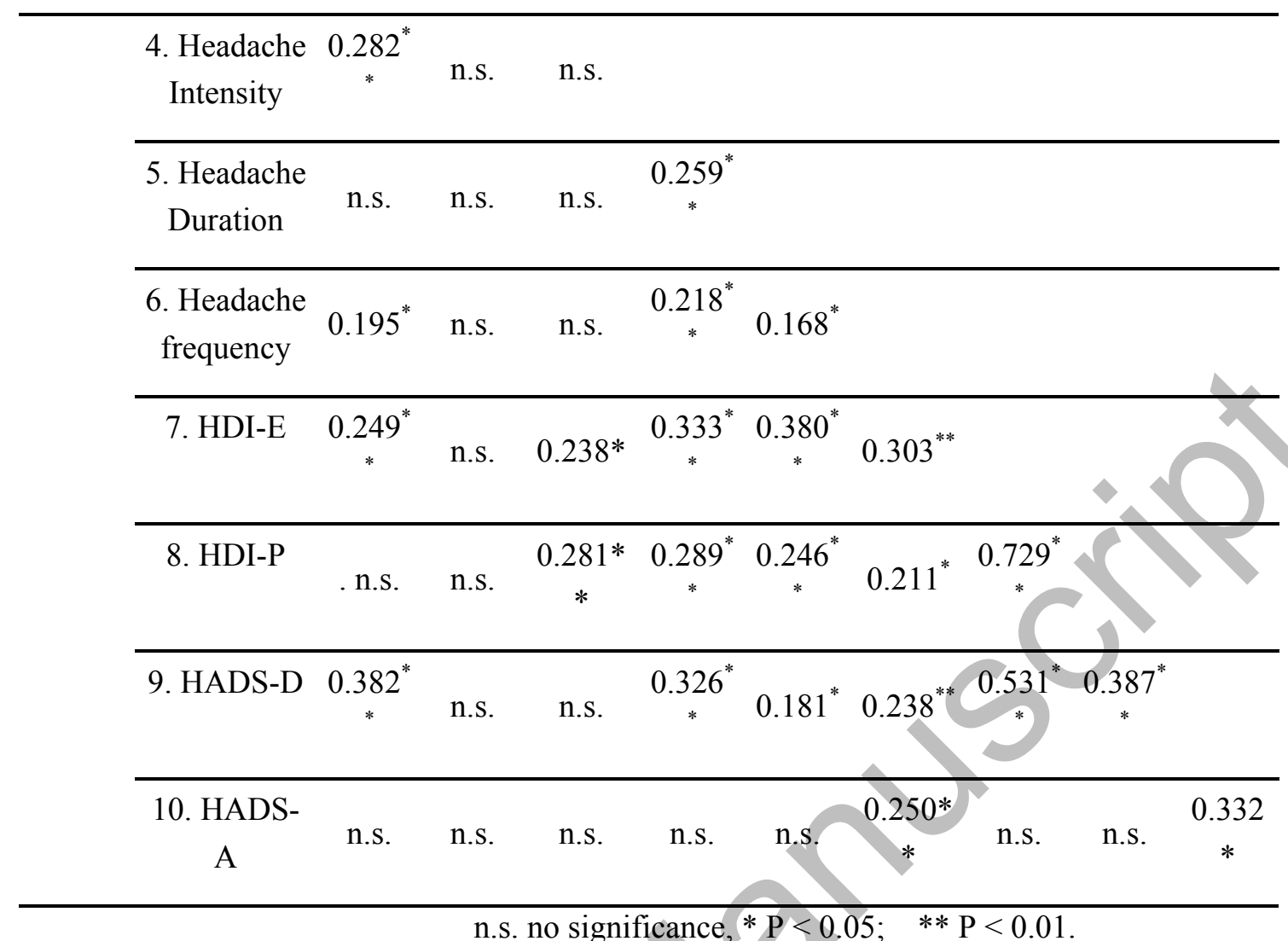

n.s. no significance, $* \mathrm{P}<0.05 ; \quad * * \mathrm{P}<0.01$.

HDI: Headache Disability Inventory (E: Emotional; P: Physical); HADS: Hospital Anxiety and Depression Scale (D: Depression; A: Anxiety) 
Table 3: Summary of Stepwise Regression Analyses to Determine Predictors of Sleep Quality for male $r^{2}=37.2 \%$ and females $r^{2}=17.4 \%$

\begin{tabular}{|c|c|c|c|c|c|c|c|}
\hline & $\begin{array}{c}\text { Independent } \\
\text { Variable }\end{array}$ & $\boldsymbol{B}$ & SE B & $\beta$ & $\mathbf{t}$ & $\mathbf{F}$ & $\mathbf{P}$ \\
\hline \multirow{5}{*}{ Males } & Step 1 & & & & & & \\
\hline & HADS-D & 0.758 & 0.157 & 0.564 & 4.82 & & \\
\hline & Step 2 & & & & & & \\
\hline & HADS-D & 0.534 & 0.187 & 0.397 & & 4.50 & $<0.001$ \\
\hline & HDI-E & & 0.075 & & & & \\
\hline \multirow{5}{*}{ Females } & Step 1 & & & & & & \\
\hline & HADS-D & 0.371 & 0.076 & 0.382 & 4.87 & 20.11 & -0.001 \\
\hline & Step 1 & & 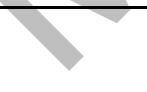 & & & \multirow{3}{*}{14.51} & \\
\hline & HADS-D & 0315 & 0.079 & 0.325 & 3.96 & & $<0.001$ \\
\hline & Headache & 0.384 & 0.178 & 0.176 & 2.15 & & \\
\hline
\end{tabular}

Note: $R^{2}=0.318$ for step $1 ; R^{2}=0.372$ for step 2 (male); $R^{2}=$ 0.146 for step $1 ; R^{2}=0.174$ for step 2 (female) $* \mathbf{P}<\mathbf{0 . 0 0 1}$

HDI-E: Headache Disability Inventory (Emotional); HADS-D:

Hospital Anxiety and Depression Scale (Depression) 